\title{
Neuro-Ophthalmological Optic Nerve Cupping: An Overview
}

\author{
Ethan Waisberg (1D) \\ Jonathan A Micieli (D) 2,3 \\ 'UCD School of Medicine, University \\ College Dublin, Belfield, Dublin, 4, \\ Ireland; ${ }^{2}$ Department of Ophthalmology \\ and Vision Sciences, University of \\ Toronto, Toronto, Ontario, Canada; \\ ${ }^{3}$ Kensington Vision and Research Centre, \\ Toronto, Ontario, Canada
}

\begin{abstract}
Optic nerve cupping or enlargement of the cup-to-disc ratio is widely recognized as a feature of glaucoma, however it may also occur in non-glaucomatous optic neuropathies. The most well-recognized non-glaucomatous optic neuropathies that cause cupping include compressive optic neuropathies, arteritic anterior ischemic optic neuropathies, hereditary optic neuropathies, and optic neuritis. Cupping is thought to consist of two main components: prelaminar and laminar thinning. The former is a shallow form of cupping and related to loss of retinal ganglion cells, whereas the latter involves damage to the lamina cribrosa and peripapillary scleral connective tissue. Differentiating glaucomatous and nonglaucomatous optic nerve cupping remains challenging even for experienced observers. Classically, the optic nerve in non-glaucomatous causes has pallor of the neuroretinal rim, but the optic nerve should not be examined in isolation. The patient's medical history, history of presenting illness, visual function (visual acuity, color vision and visual field testing) and ocular examination also need to be considered. Ancillary testing such as optical coherence tomography of the retinal nerve fiber layer and ganglion cell layer-inner plexiform layer may also be helpful in localizing the disease. In this review, we review the non-glaucomatous causes of cupping and provide an approach to evaluating a patient that presents with an enlarged cup-to-disc ratio.
\end{abstract}

Keywords: optic disc cupping, misdiagnosis of glaucoma, nonglaucomatous cupping, differential diagnosis of glaucoma, optic disc pallor

\section{Introduction}

"Cupping" is a term used to describe enlargement of the cup-to-disc ratio and is widely recognized as a feature of glaucoma; however, it is not pathognomonic. Since its discovery over 170 years ago, a large volume of the literature on optic disc cupping has accumulated, yet the mechanism is still not fully understood. Based on initial histopathological studies, the optic nerve cupping in glaucoma was thought to result from the loss of ganglion cell axon fibers and thinning and the posterior displacement of the lamina cribrosa. ${ }^{1-3}$ When intraocular pressure is high, diagnosis of glaucoma is relatively easy. Glaucoma is also well known to spare central visual acuity and color vision until late stages. It also produces characteristic visual field defects such as nasal steps and arcuate defects. Diagnosis may become challenging if intraocular pressure remains within the generally considered normal limits and optic disc cupping is present. This cupping may be physiologic or related to a nonglaucomatous process and the better recognized processes include compressive optic neuropathies, hereditary optic neuropathies and arteritic anterior ischemic optic neuropathy. Nonglaucomatous optic disc cupping is well known to occur
Correspondence: Jonathan A Micieli Kensington Vision and Research Centre, 340 College Street, Suite 50I, Toronto, Ontario, M5T 3A9, Canada

Tel + | 416 928-1335

$\mathrm{Fax}+1416928-5075$

Email jmicieli@kensingtonhealth.org 
with greater neuroretinal rim pallor and less profound excavation than seen in glaucoma and often has different visual manifestations. ${ }^{4}$ However, clinically differentiating glaucomatous and non-glaucomatous optic nerve cupping remains challenging even for experienced observers, especially since pallor is a subjective sign. When there is advanced cupping and the visual function is severely depressed, this can be even more challenging and ancillary testing such as magnetic resonance imaging of the orbits with contrast may be necessary. The history of presenting illness is also important since acute vision loss and rapid vision loss are less likely to be glaucomatous unless there is a corresponding high intraocular pressure. Reviewing old records is also usually helpful since previous optic disc edema or a normal appearance of the optic nerve with vision loss argue against glaucoma. The highest payouts for medicolegal insurance claims were found to involve missed or poorly followed intracranial tumors causing optic nerve and visual field changes. ${ }^{5}$ Trobe et al showed that $44 \%$ of eyes with nonglaucomatous optic atrophy were misdiagnosed as showing glaucoma in fundus stereophotographs by at least one observer. ${ }^{4}$ The focus of this review is to describe the non-glaucomatous optic neuropathies that may present with cupping and review clinical features that may help differentiate nonglaucomatous cupping from glaucoma. The term "cupping" in this review will refer to the enlargement of the cup-to-disc ratio determined by clinical examination.

\section{Methods}

Ovid MEDLINE, Google scholar and PubMed were searched from inception to June 20, 2021, using multiple search terms including nonglaucomatous optic disc cupping, glaucoma suspect, and glaucoma mimicker. A manual search of the references of the included studies was also conducted. Relevant articles published in peerreviewed journals were included.

\section{Mechanisms of Cupping in Non-Glaucomatous Optic Neuropathies}

In 1929, Hamann ${ }^{6}$ described a 54-year-old woman believed to have glaucoma who successfully underwent bilateral corneoscleral trephinations, but the progressive loss of visual fields continued. An x-ray of the skull confirmed the presence of an abnormality in the sellar region (likely a pituitary tumor). Over the next several years, Thiel, Dalsgaard-Nielsen, Möller all reported cases of compressive optic neuropathies that presented similarly to glaucoma. ${ }^{7}$ In 1950, Blazar and Scheie ${ }^{7}$ first used the term "pseudoglaucoma" to describe cases in which a definite cause was found to account for progressive visual field defects and atrophy of the optic nerve. Quigley and Anderson $^{8}$ reviewed stereophotographs of 78 patients with ischemic optic neuropathy and noted six cases of optic disc cupping that appeared similar to glaucoma. There was a higher proportion of patients with cupping due to arteritic anterior ischemic optic neuropathy (50\%) compared to those with the nonarteritic form (10\%). The enlarged cupping found more commonly in AAION than in NAION is likely to be multifactorial and the baseline "disc-at-risk" in the NAION group is also a contributing factor. The authors also found that optic disc pallor was more severe in those with ischemic optic neuropathy and the visual field defects were often distinct in this category of patients. This study had a major drawback in that the AAION group had a few numbers of eyes (10) when compared to the NAION groups. Similarly, neuroretinal rim pallor was found in a retrospective review by Trobe et al ${ }^{4}$ to be $94 \%$ specific for nonglaucomatous optic atrophy and focal or diffuse obliteration of the neuroretinal rim to be $87 \%$ specific for glaucoma. Quigley and Green ${ }^{1}$ were the first to demonstrate that optic disc cupping was the result of axon loss, and connective tissue remodelling.

The optic nerve head is composed of roughly 1.8 million retinal ganglion cell axons and exits the eye through the Bruch's membrane opening and the scleral outer portion of the neural canal. ${ }^{9}$ The lamina cribrosa is a meshwork that contains astrocytes, capillaries and connective tissue. In this area, oxygen and nutrients move from the laminar capillaries within the extracellular matrix and across the astrocyte basement membrane and into the optic nerve axons. ${ }^{9}$ The connective tissue within the lamina cribrosa is attached to the collagen and elastin fibers of the adjacent sclera and anchors it in place. ${ }^{10}$

Optic disc cupping in glaucomatous and nonglaucomatous optic neuropathies have been explained by Burgoyne ${ }^{11}$ to be consistent with two principal components: prelaminar and laminar thinning. Prelaminar thinning can occur due to loss of retinal ganglion cell axons and/or due to physical compression. ${ }^{12}$ The loss of prelaminar neural tissue increases the cup-to-disc ratio but is a shallow form of cupping. Prelaminar thinning is considered non-specific as it occurs in all forms of retinal ganglion cell axon loss including aging. Laminar deformation results from damage to the lamina cribrosa and peripapillary scleral connective tissue. ${ }^{12}$ Laminar deformation causes a clinically deeper 
form of cupping, and occurs in optic neuropathies in which the connective tissues of the optic nerve head have been damaged, becoming more susceptible to intraocular pressure (IOP) induced deformation. Whether the optic nerve head is initially damaged due to inflammatory, ischemic, or genetic causes, the process that leads to deformation of the damaged tissue is IOP related. ${ }^{12}$ This explains how optic nerve head damage can occur due to a non-IOP related process yet appear "glaucomatous". Recent modelling studies investigating optic nerve head biomechanics have found that laminar cupping may be a biomechanical feedback mechanism to restore mechanical homeostasis. ${ }^{13}$ This theory is also supported by studies showing that laminar cupping and thickening can have stress-lowering effects. ${ }^{14,15}$

\section{Conditions That Mimic Glaucomatous Cupping Compressive Optic Neuropathies}

Compressive optic neuropathies causing cupping have been observed in patients with pituitary adenomas, ${ }^{6,7,16-20}$ aneurysms, $^{21-24} \quad$ craniopharyngiomas $^{19,25}$ and meningiomas. ${ }^{16,17,19,26,27}$ Bianchi-Marzoli et al ${ }^{28}$ performed a masked measurement of the optic discs of 29 patients with compressive optic neuropathies and 20 age-matched controls. This study found a significantly larger cup-to-disc ratio $(0.37)$ for eyes with compressive optic neuropathies than for control eyes (0.10). Inter-eye asymmetry was also found in patients with unilateral optic nerve compression, suggesting that optic disc cupping is an acquired feature from these processes. An example of a patient with a tuberculum sellae meningioma compressing the right optic nerve is shown in Figure 1. Qu et $\mathrm{al}^{29}$ found that the appearance of a glaucoma-like optic disc was detected more frequently in patients with parasellar or intrasellar tumours than in an agematched control group. This retrospective study also found that larger tumours located closest to the opening of the optic canal had the highest likelihood to exhibit glaucoma-like cupping.

Compressive optic neuropathies can often be differentiated from glaucoma based on clinical features, such as reduced visual acuity, reduced color vision, pallor of the

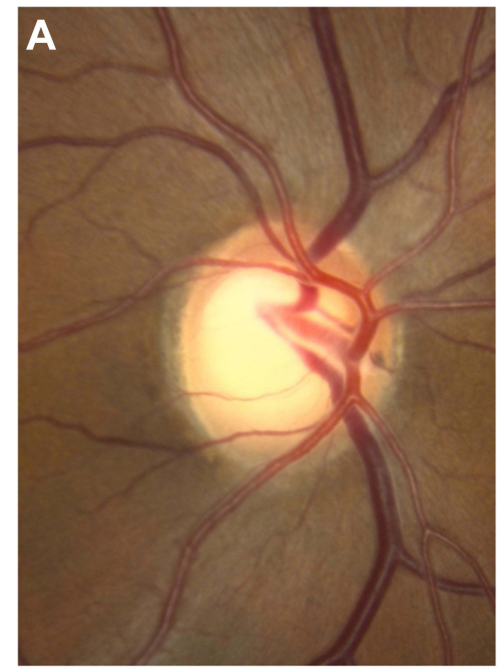

B

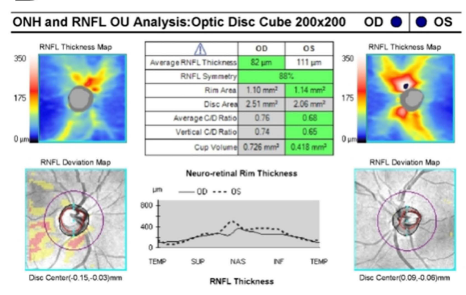

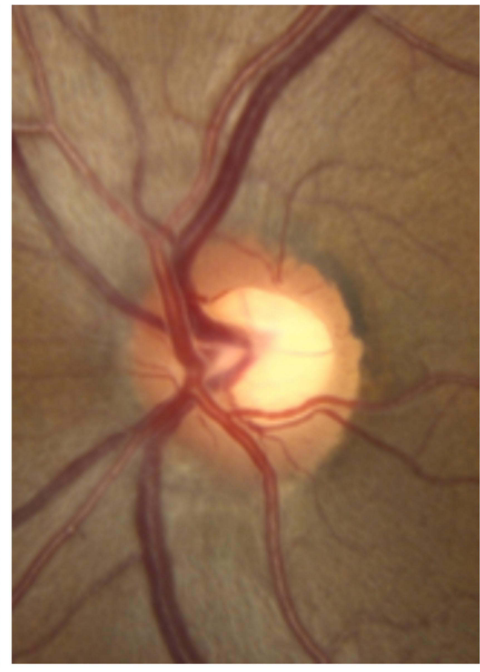
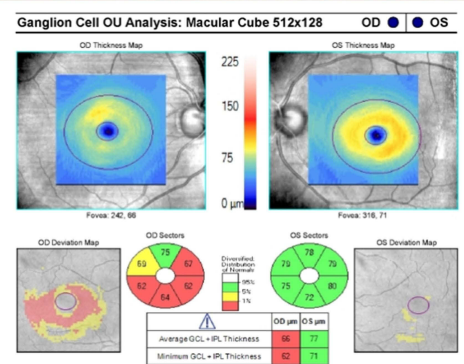
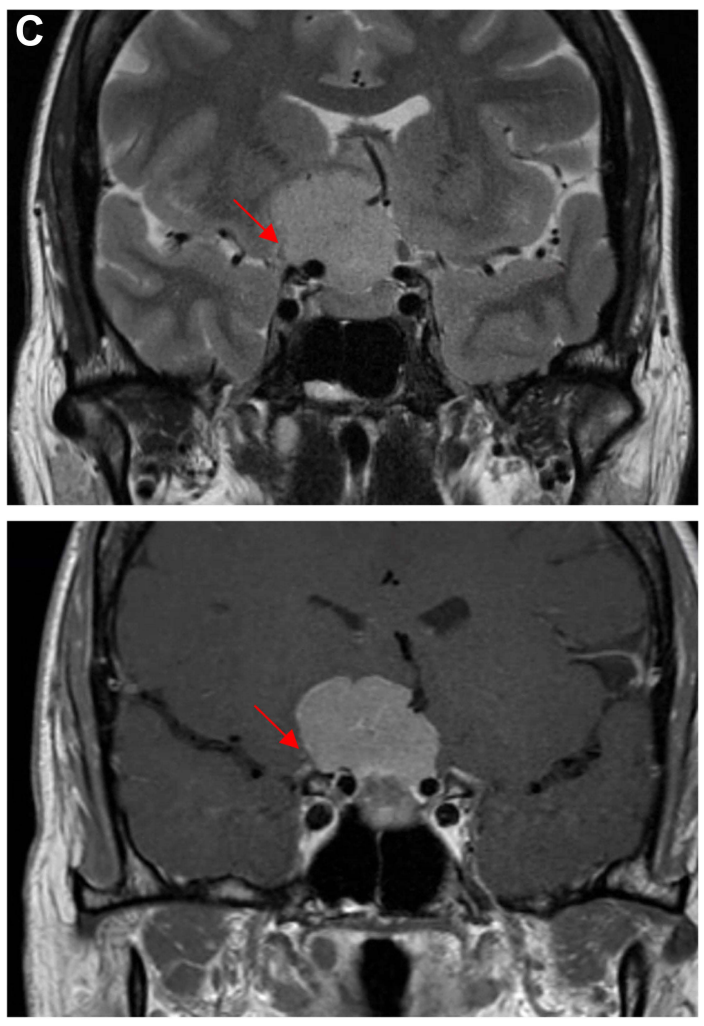

Figure I A 45-year-old woman presented with gradual onset painless vision loss in the right eye was found to have a tuberculum sellae meningioma with suprasellar extension and compression of the right optic nerve. (A) Optic disc photographs show cupping in the right optic nerve as indicated by a larger cup-to-disc ratio. (B) Optic coherence tomography (OCT) of the retinal nerve fiber layer (left panel) show atrophy of the right optic nerve, mainly in the temporal portion. OCT ganglion cell layer-inner plexiform layer (right panel) showed diffuse thinning, more prominent in the inferior macula. (C) Magnetic resonance imaging coronal T2-weighted images (above) and TIpost-contrast images (below) show a the meningioma compressing the right optic nerve (red arrow). There is mild contact with the left optic nerve. 
neuroretinal rim and visual field defects that respect the vertical meridian. Glaucoma typically spares the papillomacular bundle until the late stages, which is why central acuity and color vision tend to be spared. ${ }^{30}$ The advent of optical coherence tomography (OCT) has also been helpful since compressive optic neuropathies tend to cause atrophy of the temporal retinal nerve fiber layer (RNFL) and nasal hemi-macular ganglion cell layer-inner plexiform layer (GCIPL). In Figure 1, this 45-year-old woman had optic disc cupping greater in her right optic nerve due to a tuberculum sellae meningioma. In the right eye, she has temporal OCT RNFL thinning, which is not consistent with glaucoma and more consistent with a compressive optic neuropathy. Her visual field testing was not reliable and the OCT findings prompted neuroimaging that showed a tuberculum sellae meningioma compressing the right optic nerve.

In many previous case reports reporting optic disc cupping from compressive lesions, it was clear that the patient did not suffer from glaucoma. For example, Portney and Roth ${ }^{21}$ described a 51-year-old woman who reported reduced vision in her left eye and was found to have a "vertically oval cup elongated superiorly" due to left ophthalmic artery aneurysm. However, this patient had reduced visual acuity $(20 / 50)$, which is atypical for glaucoma and color vision, which is also often reduced, was not reported. Moreover, Ahmed et $\mathrm{al}^{31}$ presented a series of 4 of 62 patients $(6.5 \%)$ of patients thought to have normal tension glaucoma who had compressive lesions of the anterior visual pathways. However, since only the visual fields and optic nerve photographs were provided, it is not known whether the patients had reduced visual acuity, colour vision or other clinical signs to suggest a compressive optic neuropathy that would prompt neuroimaging. Some patients may have both glaucoma and a lesion in close proximity to the anterior visual pathways that are incidental in nature. This requires special attention since patients may undergo unnecessary decompressive surgery. For example, Blumenthal et $\mathrm{al}^{17}$ presented a case of an 87-year-old man with an early superior arcuate defect in the right eye and cup-to-disc ratios of $0.8 \mathrm{OD}$ and $0.6 \mathrm{OS}$, but showed an MRI image where there was barely contact with the optic chiasm, which would not be expected to have any effect on vision. The intraocular pressure was reported to be $16 \mathrm{~mm} \mathrm{Hg}$ or less in all visits, but the central corneal thickness was not reported.

Even the best clinicians may have difficulty differentiation compressive optic neuropathies from glaucoma.
Kalenak et $\mathrm{al}^{26}$ reported the case of a 66-year-old man who was initially found to have 20/20 vision in both eyes with an inferonasal step in the right eye with corresponding deep cupping of the right optic disc. There was a clear asymmetry in the optic disc photos and MRI revealed an anterior clinoid meningioma. Micieli and Margolin reported 3 patients who had significant compression of the optic nerve by a tortuous or dolichoectatic internal carotid artery and optic disc cupping without pallor of the remaining neuroretinal rim. ${ }^{32}$ All these patients had preserved visual acuity, IOP less than $21 \mathrm{mmg} \mathrm{Hg}$, open angles, and visual field defects that were typical for glaucoma. This suggests that it may not always be possible to differentiate glaucoma from compressive optic neuropathies on purely clinical grounds and MRI may be required. Some have supported a theory that vascular compression of the optic nerve by the internal carotid artery may account for a number of cases classified as normal tension glaucoma. ${ }^{33,34}$

The issue of when to obtain neuroimaging to detect a compressive optic nerve lesion in a patient with cupping of the optic nerve has been previously studied. Greenfield et $\mathrm{al}^{35}$ enrolled 29 consecutive glaucoma patients with normal intraocular pressure who underwent MRI or CT as part of their diagnostic evaluation and 44 patients with nonglaucomatous cupping. They reported that visual acuity less than 20/40, vertically aligned visual field defects, optic nerve pallor in excess of cupping and age younger than 50 years were specific signs $(77 \%, 81 \%$, $90 \%$, and $93 \%$, respectively). For patients with glaucoma, the optic nerve changes should correspond to the visual field defect. For example, a patient with an inferior notch of the optic nerve should have a corresponding superior visual field defect (Figure 2). However, if there exists a mismatch between the degree of optic disc cupping and the degree of vision field loss or there is visual acuity loss out of proportion to the optic disc cupping, a compressive optic neuropathy or other non-glaucomatous optic neuropathy should be suspected. Some patients may have anomalous or hypoplastic optic nerves, and this may make cupping difficult to appreciate in patients with visual field defects resembling glaucoma and neuroimaging should be considered in these patients. ${ }^{36}$

\section{Hereditary, Toxic and Nutritional Optic Neuropathies}

Cupping has been described in hereditary optic neuropathies (such as Dominant Optic Atrophy ${ }^{28}$ and Leber's Hereditary 
A
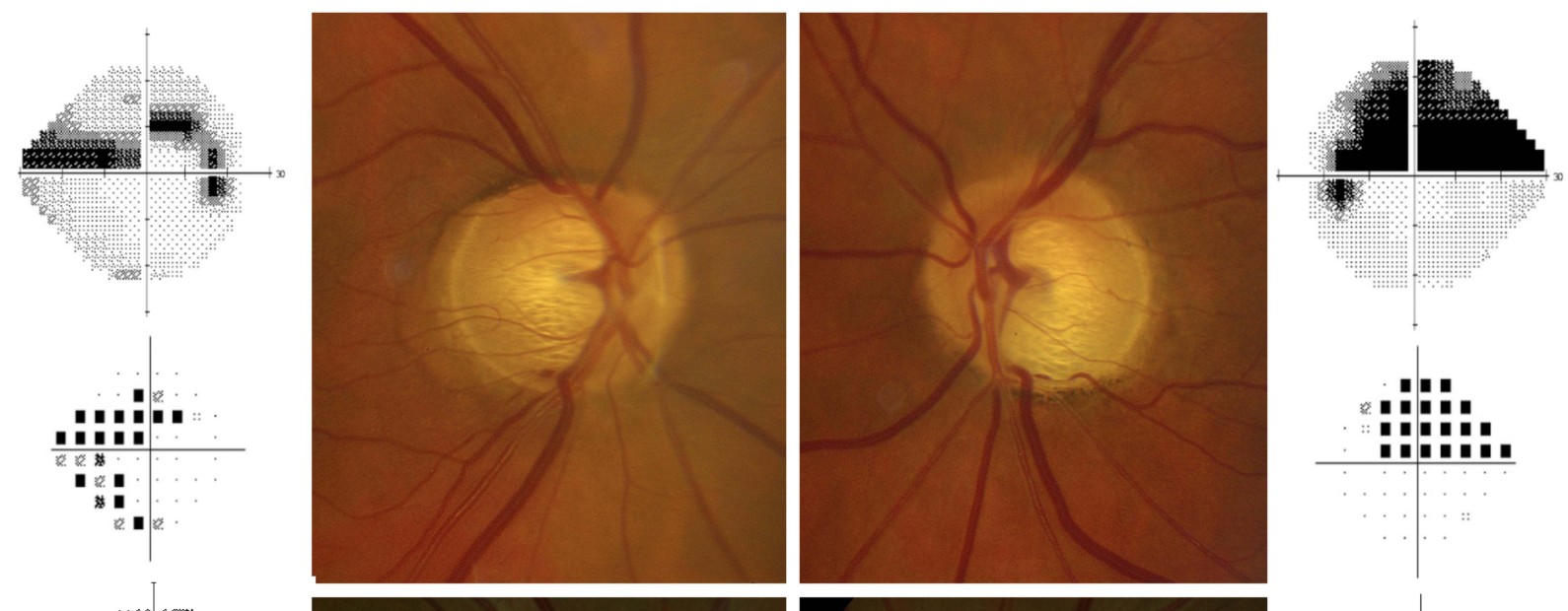

B
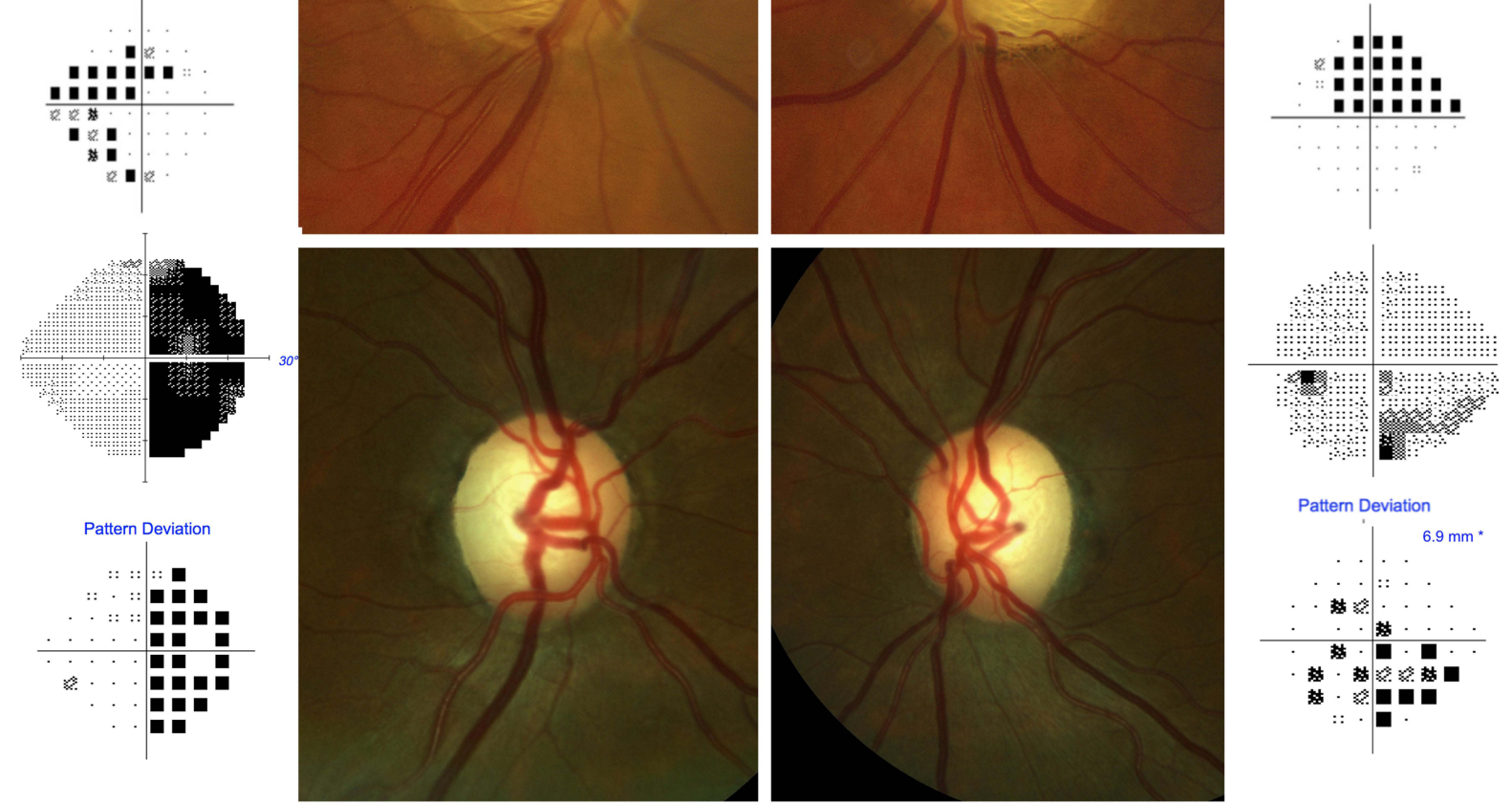

Pattern Deviation

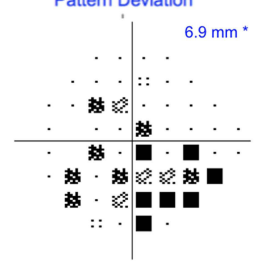

Figure 2 A comparison of glaucomatous (A) and non-glaucomatous cupping due to compression from a planum sphenoidale meningioma (B). Patient A has primary open angle glaucoma and inferior notches that correspond to the superior visual field defects in both eyes. Patient B was mistakenly diagnosed with glaucoma, but there is temporal pallor of the neuroretinal rim and the visual field defects cannot be well-correlated to the optic disc changes.

Optic Neuropathy ${ }^{20,28,37-41}$ ), toxic optic neuropathies ${ }^{42-45}$ and nutritional optic neuropathies. ${ }^{46}$ It has been hypothesized that mitochondrial dysfunction found in hereditary optic neuropathies may be involved in the underlying mechanism in both normal-tension glaucoma and primary open-angle glaucoma, accounting for the similarities in the morphologic features of the optic nerve. ${ }^{47}$ Hereditary, toxic and nutritional optic neuropathies typically do not mimic glaucoma since they primarily affect central vision (glaucoma spares central vision until later stages), they affect colour vision (glaucoma spares colour until the end) and they are typically bilateral. ${ }^{48}$ Particularly in the later stages of disease, hereditary, toxic and nutritional optic neuropathies become more difficult to differentiate from glaucoma due to the increased excavation of the optic disc (Figure 3).

All hereditary and nutritional/toxic optic neuropathies have selective involvement in the papillomacular bundle, leading to temporal pallor of the optic disc and visual field defects of central or cecocentral scotomas. ${ }^{48} \mathrm{O}^{\prime}$ Neil et al ${ }^{47}$ showed that although hereditary optic neuropathies exhibit cupping similar to that in glaucoma, shallow cups were more common in patients with Dominant Optic Atrophy (34\%) and LHON (49\%) compared to patients with glaucoma $(9 \%)$.

The most common hereditary optic neuropathy is dominant optic atrophy (DOA). Fournier et $\mathrm{al}^{49}$ found that $89 \%$ of patients with DOA had significant cupping of the optic disc in at least one eye ( $>0.5$ cup-to-disc ratio). This study also found a temporal wedge-shaped area of excavation in $78 \%$ of eyes with DOA. Kim et $\mathrm{al}^{50}$ found that optical coherence tomography could be used to accurately distinguish eyes with DOA from glaucoma by the pattern of retinal nerve fibre layer damage. The temporal measurements were outside of the $95 \%$ normal limit in $91 \%$ of eyes with DOA, and the pattern of damage was symmetrical bilaterally. A typical case of this is shown in the Figure 3.

Leber's Hereditary Optic Neuropathy (LHON) typically presents with painless, bilateral vision loss that may 


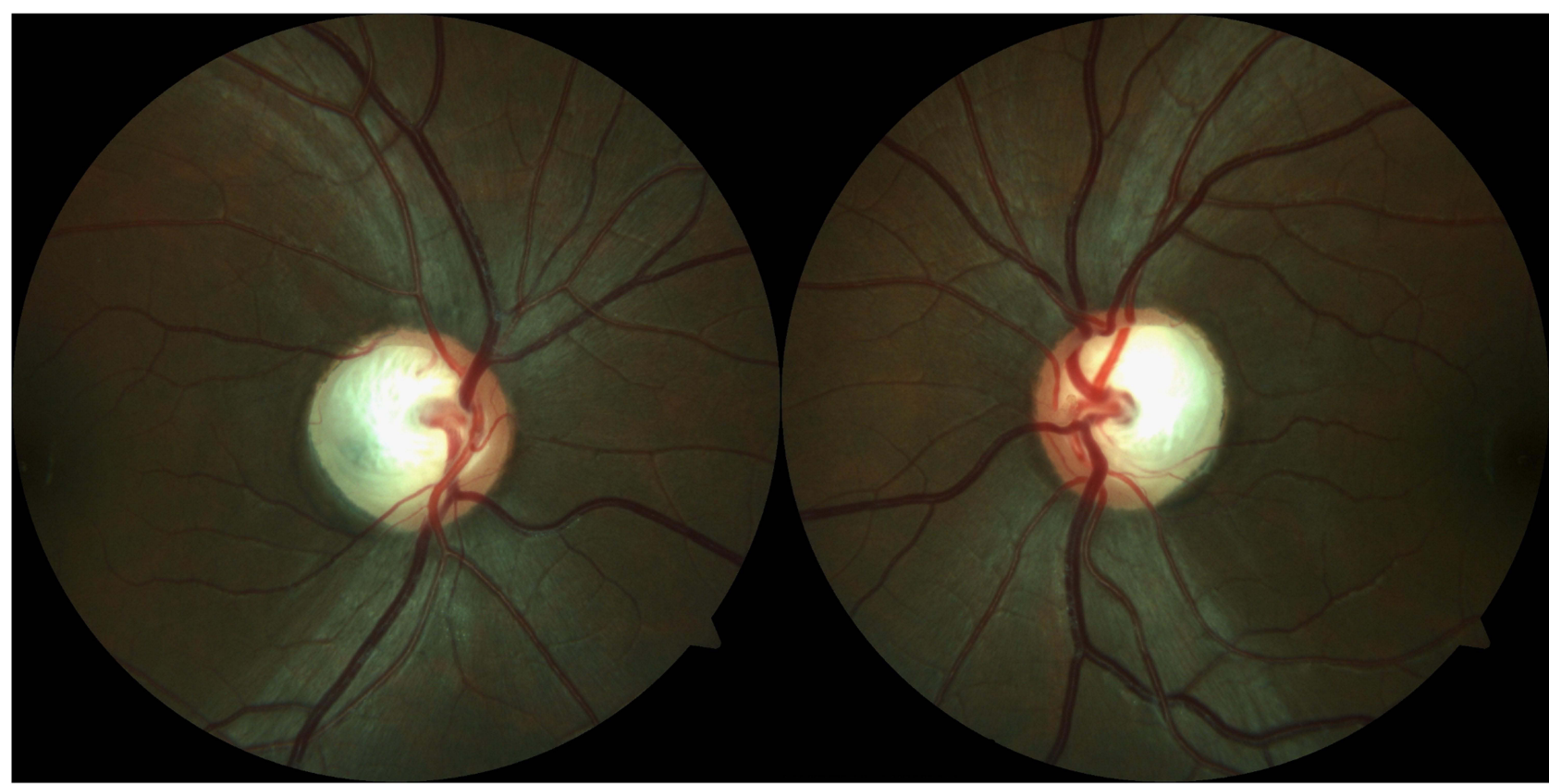

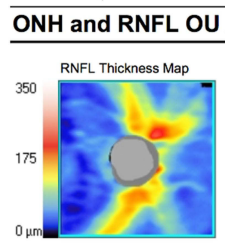

RNFL Deviation Map

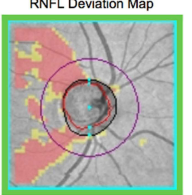

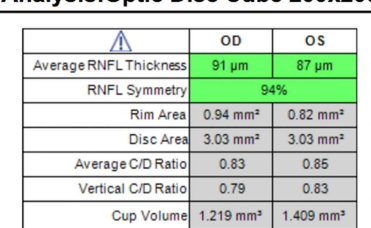

Neuro-retinal Rim Thickness

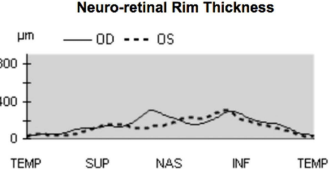

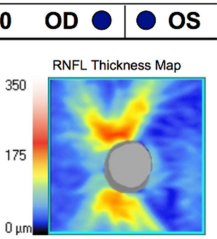

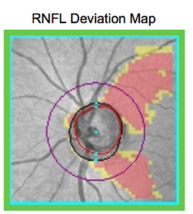

Ganglion Cell OU Analysis: Macular Cube 512x128

OD $\bigcirc \bigcirc$ OS
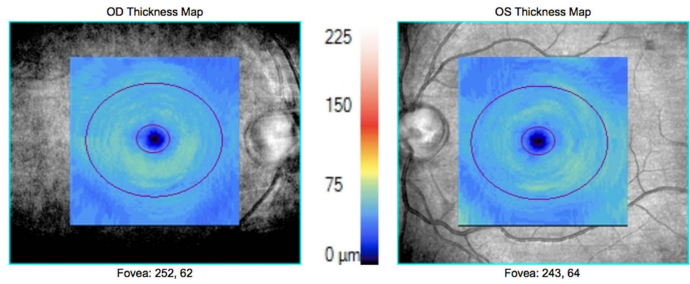

Fovea: 243,64
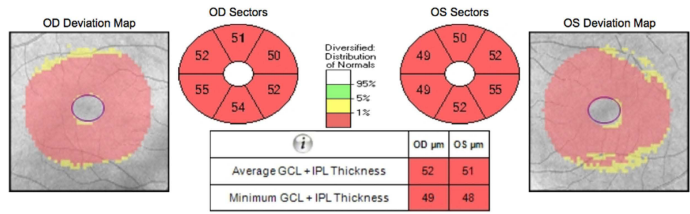

Figure 3 An 18-year-old man with dominant optic atrophy (DOA). The fundus photographs (top panel) show optic nerves with temporal pallor and there is dropout of the retinal nerve fiber layer in the papillomacular bundle. Optic coherence tomography of the retinal nerve fiber layer (bottom left panel) shows loss of the temporal portion of the optic nerves. Optical coherence tomography of the macular ganglion cell layer-inner plexiform layer shows diffuse atrophy in both eyes.

be sequential or simultaneous. Fundoscopy can show a mildly hyperemic optic disc with peripapillary telangiectatic vessels; however, funduscopic abnormalities can be absent in up to half of patients with LHON. ${ }^{48,51}$ Eyes with previous LHON have been shown to have a significantly larger disc area, cup-to-disc ratio, and thinner retinal nerve fibre layer thickness compared with controls. ${ }^{52}$

Toxic optic neuropathies may occur after the use of medications, such as ethambutol, linezolid or toxic substances such as methanol with symptoms usually appearing 12-24 hours after exposure with respect to methanol. ${ }^{44}$ Masvidal et $\mathrm{al}^{53}$ reported a case of a 55-year-old man with ethambutol optic neuropathy with cupped optic discs bilaterally, and disc pallor. After discontinuation of the medication, visual acuity improved from 20/30 to 20/70 in both eyes, however optic disc pallor and cupping remained. Stelmach et $\mathrm{al}^{42}$ reported a case of a 17 -yearold that developed sudden-onset visual failure following ingestion of methanol. The dissolution of methanol produces formaldehyde, which then converts to formic acid, causing necrosis of the optic nerve and retinal ganglionic cells. $^{54}$ Fundus examination on presentation showed venous engorgement and bilateral optic disc hyperemia, and subsequently showed optic disc atrophy and glaucoma-like cupping.

Toxic optic neuropathy is one of the most common forms of non-glaucomatous optic disc cupping in younger age patients, especially in the Middle East. After the 
COVID-19 pandemic, multiple methanol toxicity outbreaks in these countries were noted with concomitant toxic optic neuropathies. Due to high stigma of alcohol intake in these societies, taking a good history is valuable in diagnosis and avoiding glaucoma evaluation and unnecessary treatments. Many case reports and case series of optic disc cupping due to methanol toxicity have been reported in recent years from these countries. ${ }^{55-58}$

Nutritional-deficiency optic neuropathy (NON) causes a progressive loss of vision, and in the early stages of the deficiency, the optic disc may appear normal or slightly hyperemic and optic atrophy occurs in later stages (appearing as temporal pallor). ${ }^{46,59}$ Senthil et al ${ }^{46}$ reported 3 cases referred to as normal tension glaucoma but were ultimately diagnosed with nutritional-deficiency optic neuropathy. All patients in their series had enlarged cup-to-disc ratios and OCT RNFL showed thinning that involved the vertical segments of the optic disc. However, all patients had noticeable dropout of the papillomacular bundles and corresponding pallor of the temporal optic disc. The central scotomas and reduced color vision of each patient were also not consistent with glaucoma, indicating that the diagnosis could be made on clinical grounds.

\section{Inflammatory}

Optic neuritis ${ }^{20,60-62}$ typically results in painful subacute vision loss and is a result of demyelination. It can be idiopathic or seen in the context of neurological conditions, such as multiple sclerosis or neuromyelitis optica spectrum disorders. ${ }^{63}$ Rath et al $^{62}$ studied consecutive optic nerves of 35 patients with non-arteritic anterior ischemic optic neuropathy (NAION) and 24 eyes with optic neuritis. They found that the pattern of pallor was also helpful in differentiating NAION from optic neuritis as the former typically had altitudinal segmental pallor, whereas optic neuritis tended to have temporal pallor. Using optical coherence tomography, Rebolleda et $\mathrm{al}^{61}$ studied 50 patients that had a single episode of unilateral optic neuritis and compared them to healthy controls. They found that OCT measured cup-to-disc ratios that were greater in the affected eye by an average of 0.12 . However, it should be kept in mind that the cup-to-disc ratio obtained by OCT tends to be higher than that found by slit-lamp evaluation. ${ }^{64,65}$ It was not surprising that this study also found that the cup-to-disc ratio was inversely correlated with visual acuity and the OCT RNFL average thickness. Zhang et $\mathrm{al}^{20}$ reported the cases of four patients with optic neuritis presenting with diffuse optic disc cupping. In many of these patients, optic disc pallor and excavation of the optic disc were also seen. An example of patient with optic disc cupping after optic neuritis is seen in Figure 4.

\section{Ischemic}

Ischemic optic neuropathy is the loss of function of a portion of the optic nerve due to ischemia and is categorized as anterior or posterior and arteritic and nonarteritic. Anterior ischemic optic neuropathies present with optic disc edema in the acute period and are far more common than posterior ischemic optic neuropathies, which are almost always seen in giant cell arteritis or postnon-ocular surgeries. Arteritic refers to a vasculitis and this is most often giant cell arteritis. Hayreh ${ }^{3}$ hypothesized that three factors are responsible for optic nerve cupping in ischemic optic neuropathy: 1) destruction of prelaminar neural tissue, 2) retrolaminar fibrosis causing backward bowing of the lamina cribrosa and 3) destruction of laminar neural tissue and weakness of laminar connective tissue. As previously mentioned, cupping occurs more often and to a greater degree in arteritic anterior ischemic optic neuropathy (AAION) compared to NAION. ${ }^{8}$

In arteritic anterior ischemic optic neuropathy ${ }^{66-69}$ (AAION), optic nerve cupping is a well-recognized outcome. Danesh-Meyer et al ${ }^{68}$ conducted an observational case series on 92 eyes of with AAION and 113 eyes with NAION and found optic nerve cupping in 85 of $92(92 \%)$ of AAION eyes compared to 3 of 113 (2\%) of eyes with NAION. In the AAION group, the cup-to-disc ratio was of the normal eye was on average 0.33 compared to $0.85 \mathrm{~mm}$ in the affected eye. The NAION optic discs were classified as having segmental pallor $(72 \%)$ or diffuse pallor $(28 \%)$ rather than prominent cupping. This study made it very clear that the end-stage optic disc appearance is very different in AAION compared to NAION and an example of this is shown in Figure 5 of patients with AAION and NAION. It is thought that there is preservation of some blood flow in NAION since the pathophysiology likely involves transient hypoperfusion of the optic nerve head. This is in contrast to giant cell arteritis and AAION, which involves more dramatic ischemia likely involving occlusion of the posterior ciliary arteries and even the ophthalmic artery in some cases. It is also possible that the "disc-at-risk", the optic nerve with a small or absent physiologic cup, considered a necessary substrate for NAION, may make it more difficult to appreciate cupping. However, the very low recurrence rate of NAION in an 

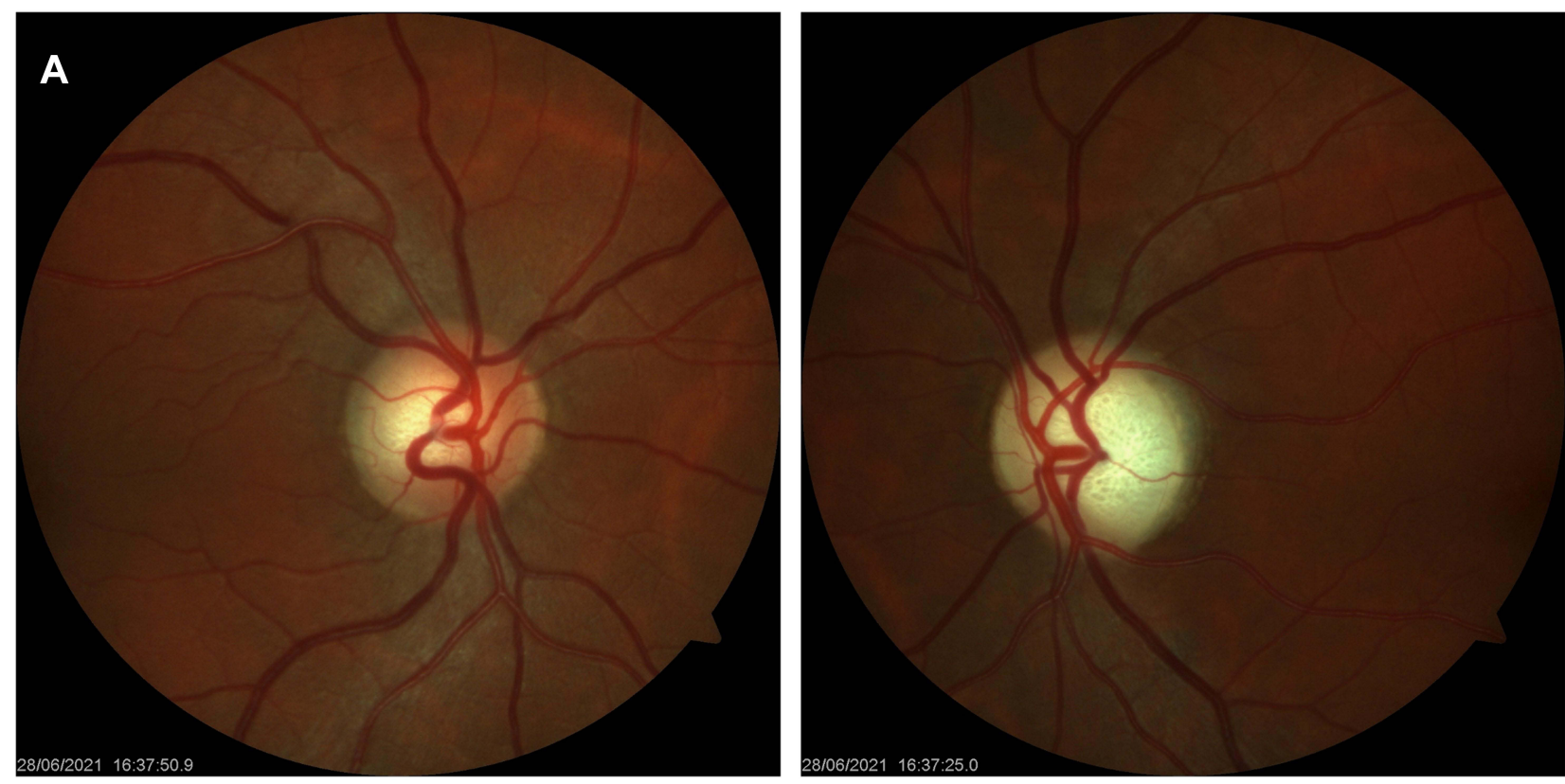
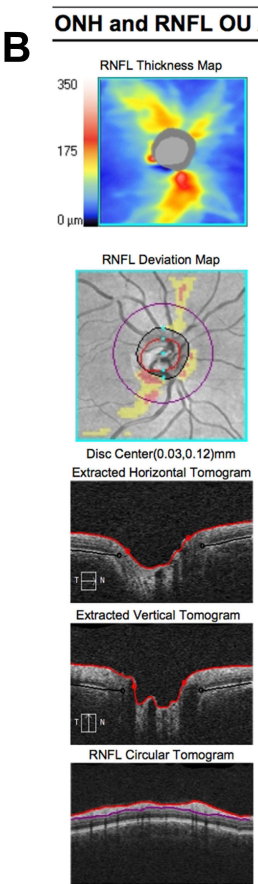
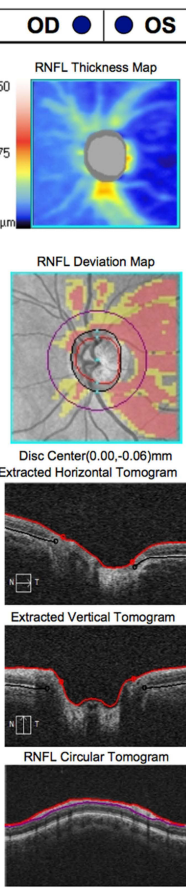
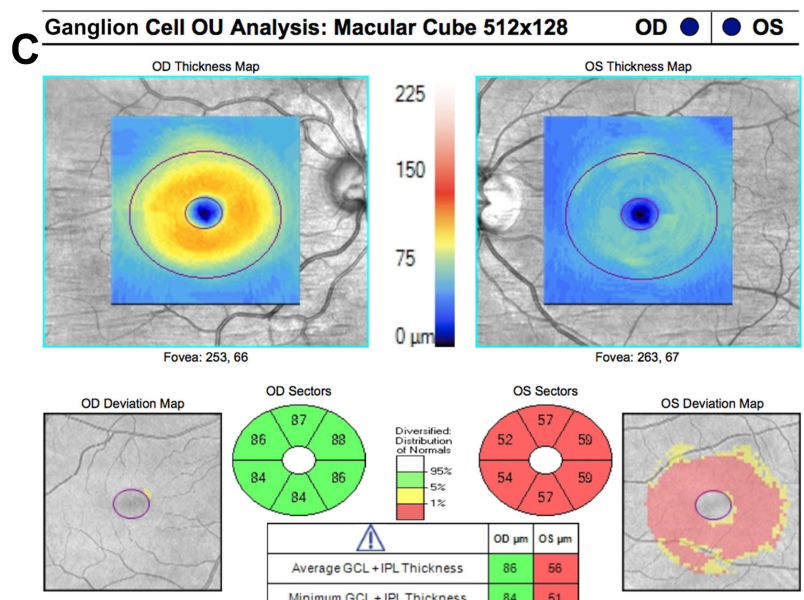

OD Sectors
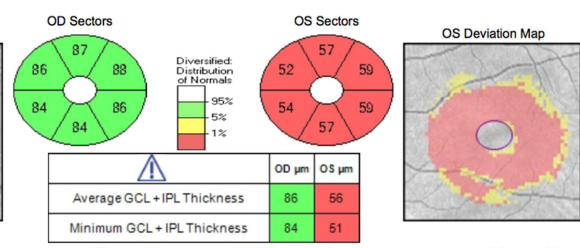

OD Horizontal B-Scan

BScan: 66

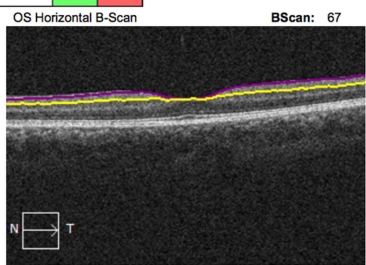

Figure 4 (A) Optic disc photographs of a 37-year-old woman who had idiopathic left optic neuritis. This photograph demonstrates an enlarged cup-to-disc ratio and pallor of the neuroretinal rim in the left eye. This photograph was taken 10 years after the initial optic neuritis attack. (B) Optical coherence tomography of the retinal nerve fiber layer shows left superior, inferior and temporal atrophy and the ganglion cell analysis (C) shows diffuse atrophy in the left eye.

eye is likely related to a small increase in the cup-to-disc ratio seen with optic atrophy in this setting, resulting in the absence of a "disc-at-risk". Indeed, Contreras et $\mathrm{al}^{70}$ reported that following the development of NAION, $48 \%$ of eyes had a cup-to-disc ratio that differed from the fellow eye by more than 0.1 .

An assessment of cupping by the minimum rim width at Bruch's membrane opening (MRW-BMO) is a metric that has shown value in differentiating glaucomatous and nonglaucomatous optic neuropathies including ischemic optic neuropathies. Leaney et $\mathrm{al}^{71}$ compared 27 patients with normal tension glaucoma to 54 patients with non-glaucomatous optic neuropathies, including 22 with ischemic optic neuropathy. They determined the MRW-BMO using Spectralis OCT scans and found that MRW-BMO measures had a high level of sensitivity and specificity for differentiating 


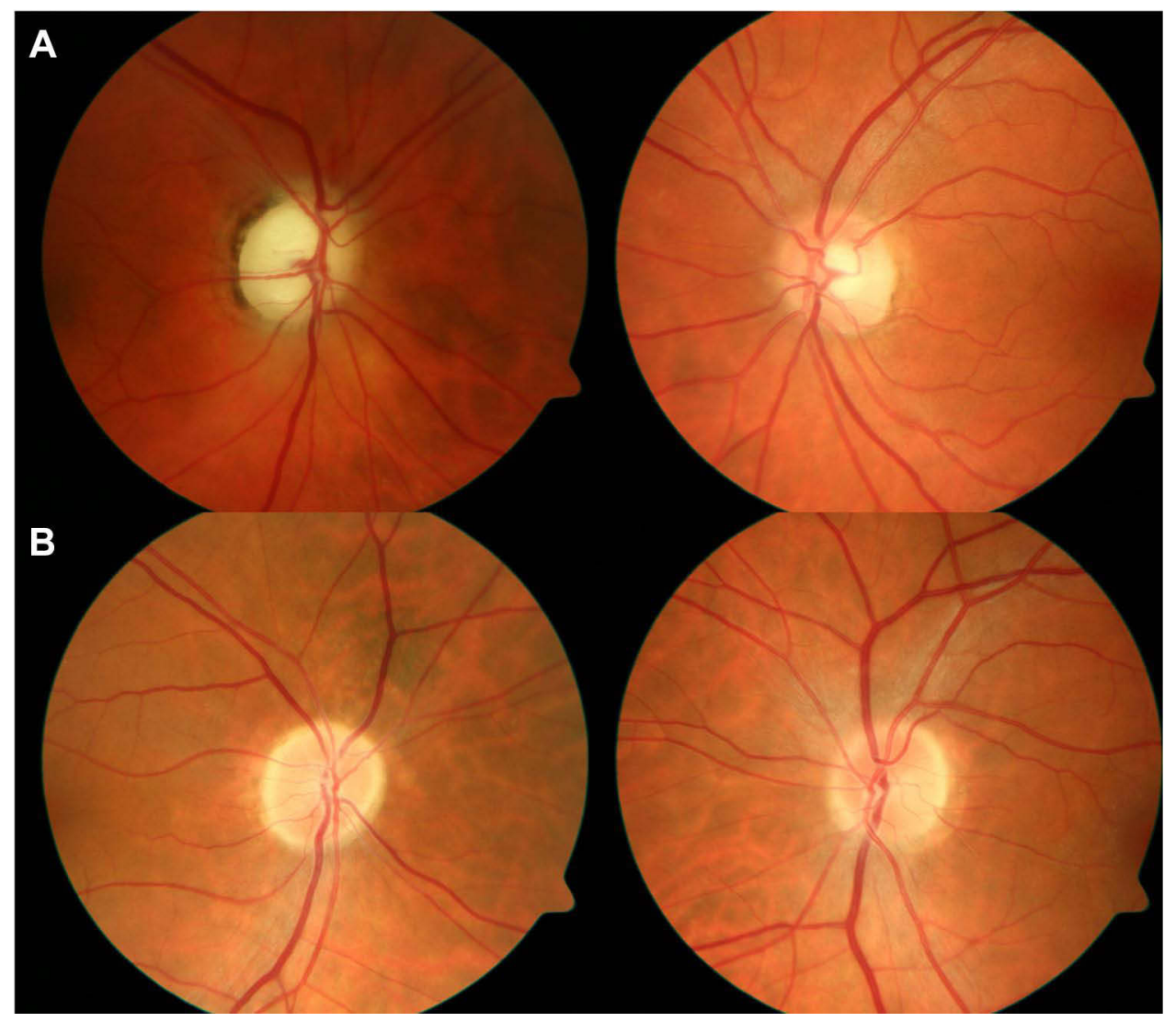

Figure 5 A comparison of optic disc cupping in arteritic anterior ischemic optic neuropathy (AAION; A) compared to non-arteritic anterior ischemic optic neuropathy (NAION; B) six months after the acute insult. Both patients had optic disc pallor in the right eye. Notice the much more extensive cupping in the AAION case compared to the NAION case.

non-glaucomatous optic neuropathies from glaucoma. When comparing glaucomatous optic neuropathies to ischemic optic neuropathies, the positive and negative predictive values were 0.77 and 0.70 , respectively. Similarly, Resch et $\mathrm{al}^{72}$ found that patients with NAION had significantly larger global BMO-MRW values compared to patients with glaucoma.

Posterior ischemic optic neuropathy (PION) is a much rarer form of ischemic optic neuropathy and is considered a watershed infarct in a vulnerable arterial territory. Specifically, this is the pial capillary plexus that surrounds the optic nerve and is derived from collateral branches of the ophthalmic artery. In the acute setting, the optic nerve appears normal in those with PION and pallor is thought to be a characteristic chronic feature. Like anterior ischemic optic neuropathy, PION can be arteritic (related to GCA) or non-arteritic (typically related to post-operative vision loss). Hayreh reported that there was no difference in the optic disc pallor among the different types of PION and in a retrospective study of 42 patients with non-arteritic PION, an increased cup size was found in 2 eyes. $^{73}$
Significant cupping in non-arteritic PION is mainly limited to case reports and considered rare. ${ }^{74}$

\section{Other Optic Neuropathies (Infection, Traumatic)}

Optic neuropathies other than compressive, hereditary, inflammatory, and ischemic are much rarer in the Western world. Case reports of other types of optic neuropathies with prominent cupping in the later stages of the disease have been reported, however. These include infectious optic neuropathies, particularly those caused by syphilis. Mansberger et $\mathrm{al}^{75}$ presented a case of a 52-yearold woman with a history of neurosyphilis and chorioretinitis who was referred for optic disc cupping and worsening vision. She had been treated with intramuscular penicillin-G 4 years prior, but it remained unknown whether this was truly a change produced by syphilis. Rosdahl et al $^{76}$ reported the case of a 49-year-old man with neurosyphilis presenting with symmetric optic nerve cupping, significant temporal thinning of the RNFL and in the macula and loss of macular thickness in the superior 
hemisphere of the left eye. However, it is not known as to when these visual field defects were truly from syphilis or whether he had optic disc cupping related to glaucoma and also had syphilis. Traumatic optic neuropathy may also result in cupping, but evidence is limited to case reports. Powell et $\mathrm{al}^{77}$ reported the case of a 41-year-old male with a unilateral optic neuropathy following a medial orbital wall fracture. Examination revealed optic nerve pallor in the right eye, a significant visual field defect in the right eye, asymmetric cupping of the optic nerve, and an asymmetric colour deficit.

\section{Congenital Causes}

Hypoxic ischemic encephalopathy (HIE) is a dysfunction caused by oxygen deprivation in the brain of a newborn. ${ }^{78}$ Hypoxic ischemic damage to periventricular white matter can result in periventricular leukomalacia, which is a major cause of visual impairment in children born preterm. $^{79}$ Periventricular leukomalacia $^{80,81}$ (PVL) has been reported to cause glaucoma-like cupping in several cases. Jacobson et $\mathrm{al}^{79}$ proposed that early PVL (occurring before 28 weeks of gestation) may be associated with small-sized optic discs, while lesions after 28 weeks of gestation are associated with large cupping and reduced area of the neuro-retinal rim. PVL is believed to cause glaucoma-like cupping due to transsynaptic degeneration, which occurs after damage to the retrogeniculate pathways during the perinatal period. ${ }^{78}$ Optic atrophy in periventricular leukomalacia may occur due to damage to the anterior visual pathways. Groth et $\mathrm{al}^{80}$ recommended in a clinical review of two PVL patients to differentiate PVL-related cupping from glaucoma using the features of: horizontal cupping, a patient history of premature birth, minimal nasal displacement of vessels (or none), and/or inferior visual field defects with superior optic nerve thinning.

In optic disc coloboma, a clearly delineated, white, bowl-shaped, excavation occupies an enlarged optic disc. $^{82}$ Numerous optic disc colobomas ${ }^{7,83-86}$ mimicking glaucomatous cupping have been reported in the literature. Colobomatous cupping can be difficult to differentiate from glaucomatous cupping, particularly if accompanied by nerve fibre bundle defects. ${ }^{83}$ Key features to differentiate colobomatous cupping from glaucoma typically include: an unusual displacement of vasculature caused by the coloboma, presence of amblyopia from a young age and the lower half of the disc having the deepest cupping. $^{83}$
Morning glory disc anomaly (MGDA) is characterized by a funnel-shaped excavation of the optic nerve head, peripapillary atrophy, and retinal vessels emerging from the disc edge in an abnormal radial pattern. ${ }^{87}$ Using OCT analysis of a case of isolated MGDA, Srinivasan et $\mathrm{al}^{88}$ showed an enlarged optic cup and disc with increased retinal nerve fiber layer thickness temporally and reduced macular thickness. Saraswat et $\mathrm{al}^{89}$ similarly reported an enlarged optic cup and disc with RNFL thinning in a patient with MGDA, however macular thickness was normal.

Eyes with megalopapilla have enlarged central cups, which in rare cases can obliterate portions of the neural rim. ${ }^{88}$ Due to the enlargement of the cup, megalopapilla can sometimes be confused with cases of severe glaucoma; however, in megalopapilla the disc area is significantly larger when compared to glaucomatous eyes. ${ }^{90}$ The rim area of the megalopapilla is also significantly larger than in advanced glaucoma. ${ }^{91}$

\section{High Myopia}

Discs with high myopia require special attention, as high myopia is a risk factor in primary open-angle glaucoma. ${ }^{92}$ Myopia can also cause visual field defects mimicking glaucoma in as high as $16.1 \%$ of patients. ${ }^{93}$ Compared to normal eyes, myopic eyes typically have an optic disc that is: larger, more shallow, oval-shaped, obliquely oriented, and presence of neuroretinal rim thinning and peripapillary atrophy. ${ }^{94,95}$

The "crescent moon" sign reported by Kim et al ${ }^{96}$ is a useful screening tool for early detection of glaucoma when myopic tilted discs are encountered. The sign is defined as a discontinuity between the inferior or superior optic rim margin and the temporal optic rim margin, and is highly sensitive (90.0-91.4\%).

\section{Approach to the Patient with Optic Disc Cupping}

As outlined above, non-glaucomatous optic neuropathies may present with an enlarged cup-to-disc ratio and mimic glaucoma. The differentiation involves not only studying the appearance of the optic disc but also the patient's history, medical history, family history and visual function need to be accounted for. Glaucoma is well known to be asymptomatic, particularly in the early to mid-stages, and there should be a high suspicion of non-glaucomatous optic neuropathy in patients with acute, subacute or progressive vision loss, especially in the presence of normal intraocular pressure. 
A history of systemic symptoms (eg temporal headache, jaw claudication) or pain with eye movements suggests a nonglaucomatous optic neuropathy. The visual function is also very important as glaucoma is well known to produce characteristic visual field defects (eg Nasal step and arcuate scotoma) and spare color vision until the end. In a patient with a visual field defect respecting the vertical meridian or color vision loss that is out of proportion to the visual acuity, a non-glaucomatous optic neuropathy should be suspected. Unilateral or asymmetric damage tends to favor nonglaucomatous causes, but unilateral glaucoma is possible especially if there is a unilateral process such as pseudoexfoliation. Importantly, the optic nerve should be carefully assessed for the presence of pallor and the cupping should be studied in relation to the visual field. The cupping in glaucoma should match the visual field (eg Inferior notch should have a superior visual field defect) and if the visual field defect appears out of proportion to the degree of cupping, a non-glaucomatous optic neuropathy is more likely. Some circumstances may be difficult, including those with anomalous, hypoplastic optic nerves or those with end-stage disease (complete cup and severely compromised vision). These patients often require magnetic resonance imaging of the orbits with contrast to assess for compression of the anterior visual pathways and blood work targeted at their history and examination (eg erythrocyte sedimentation rate and C-reactive protein in patients with symptoms suggestive of giant cell arteritis). Even if the initial presentation is ambiguous, the temporal evolution of the patient such as rapid progression, improvement or stability will also lend clues to the diagnosis. For example, progression of visual function despite normal or low intraocular pressures is unusual for glaucoma and a non-glaucomatous optic neuropathy should be considered. Finally, collaborative work is important, and an opinion from a neuro-ophthalmologist or glaucoma specialist should be obtained when the diagnosis is in doubt since these specialists tend to have more expertise in evaluating optic neuropathies.

\section{Conclusion}

Non-glaucomatous cupping can be seen in a variety of disorders, particularly compressive optic neuropathies, arteritic anterior ischemic optic neuropathies, toxic optic neuropathies, hereditary optic neuropathies, and optic neuritis. The patients' history, examination and ancillary testing such as optical coherence tomography are useful in making this differentiation. Detailed assessment of the optic nerve in relation to the visual function is critical as glaucomatous cupping should directly correlate to the visual field deficits. In difficult cases, referral to experts, such as neuro-ophthalmologists, may be required and additional investigations such as magnetic resonance imaging and ancillary blood testing to uncover the underlying cause.

\section{Funding}

This research did not receive any specific grants from funding agencies in the public, commercial, or not-forprofit sectors.

\section{Disclosure}

The authors report no conflicts of interest in this work.

\section{References}

1. Quigley HA, Green WR. The histology of human glaucoma cupping and optic nerve damage: clinicopathologic correlation in 21 eyes. Ophthalmology. 2020;127(4):S45-S69. doi:10.1016/j.ophtha.2020. 01.035

2. Weinreb RN, Aung T, Medeiros FA. The pathophysiology and treatment of glaucoma: a review. JAMA. 2014;311(18):1901. doi:10.1001/ jama.2014.3192

3. Hayreh SS. Pathogenesis of cupping of the optic disc. $\mathrm{Br}$ J Ophthalmol. 1974;58(10):863.

4. Trobe JD, Glaser JS, Cassady J, Herschler J, Anderson DR. Nonglaucomatous excavation of the optic disc. Arch Ophthalmol. 1980;98(6):1046-1050. doi:10.1001/archopht.1980.01020031036004

5. Mathew RG, Ferguson V, Hingorani M. Clinical negligence in ophthalmology: fifteen years of national health service litigation authority data. Ophthalmology. 2013;120(4):859-864. doi:10.1016/j. ophtha.2012.01.009

6. Hamann JI. Beitrag·zur Diagnose und Therapie von Hypophysentumoren. Ophthalmologica. 1929;68(6):317-330. doi:10.11 59/000296770

7. Blazar HA, Scheie HG. Pseudoglaucoma. AMA Arch Ophthalmol. 1950;44(4):499-513. doi:10.1001/archopht.1950.00910020509001

8. Quigley H, Anderson DR. Cupping of the optic disc in ischemic optic neuropathy. Trans Sect Ophthalmol Am Acad Ophthalmol Otolaryngol. 1977;83(5):755-762.

9. Anderson DR. Ultrastructure of human and monkey lamina cribrosa and optic nerve head. Arch Ophthalmol Chic Ill. 1969;82(6):800-814. doi:10.1001/archopht.1969.00990020792015

10. Morrison JC, Jerdan JA, L'Hernault NL, Quigley HA. The extracellular matrix composition of the monkey optic nerve head. Invest Ophthalmol Vis Sci. 1988;29(7):1141-1150.

11. Burgoyne C. The morphological difference between glaucoma and other optic neuropathies. J Neuro-Ophthalmol off J North Am NeuroOphthalmol Soc. 2015;35(Suppl 1):S8-S21. doi:10.1097/ WNO.0000000000000289

12. Burgoyne CF, Downs JC. Premise and prediction-how optic nerve head biomechanics underlies the susceptibility and clinical behavior of the aged optic nerve head. J Glaucoma. 2008;17(4):318-328. doi:10.1097/IJG.0b013e31815a343b

13. Crawford downs J, Roberts MD, Sigal IA. Glaucomatous cupping of the lamina cribrosa: a review of the evidence for active progressive remodeling as a mechanism. Exp Eye Res. 2011;93(2):133-140. doi:10.1016/j.exer.2010.08.004 
14. Sigal IA, Flanagan JG, Ethier CR. Factors influencing optic nerve head biomechanics. Invest Ophthalmol Vis Sci. 2005;46 (11):4189-4199. doi:10.1167/iovs.05-0541

15. Sigal IA. Interactions between geometry and mechanical properties on the optic nerve head. Invest Ophthalmol Vis Sci. 2009;50 (6):2785-2795. doi:10.1167/iovs.08-3095

16. Hupp SL, Savino PJ, Schatz NJ, Sergott RC, Bosley TM. Nerve fibre bundle visual field defects and intracranial mass lesions. Can J Ophthalmol J Can Ophtalmol. 1986;21(6):231-235.

17. Blumenthal EZ, Girkin CA, Dotan S. Glaucomatous-like cupping associated with slow-growing supra-sellar intracranial lesions. NeuroOphthalmol. 2006;30(5):111-115. doi:10.1080/01658100600980974

18. Drummond SR, Weir C. Chiasmal compression misdiagnosed as normal-tension glaucoma: can we avoid the pitfalls? Int Ophthalmol. 2010;30(2):215-219. doi:10.1007/s10792-0099308-9

19. Choudhari N, Fudnawala V, Neog A, George R. Cupped disc with normal intraocular pressure: the long road to avoid misdiagnosis. Indian J Ophthalmol. 2011;59(6):491. doi:10.4103/0301-4738.86320

20. Zhang YX, Huang HB, Wei SH. Clinical characteristics of nonglaucomatous optic disc cupping. Exp Ther Med. 2014;7(4):995-999. doi:10.3892/etm.2014.1508

21. Portney GL, Roth AM. Optic cupping caused by an intracranial aneurysm. Am J Ophthalmol. 1977;84(1):98-103. doi:10.1016/00029394(77)90332-4

22. Kulkarni AA, Hope-Ross M, Beale DJ, Byrne JV. Glaucoma mimicked by carotid-ophthalmic artery aneurysm: a rare insidious cause of progressive visual loss. Eye. 2000;14(3):405-406. doi: $10.1038 /$ eye. 2000.105

23. Pincelli Netto M, Ferrari PV, Herrerias BT, Hirai FE, Gracitelli CPB. Internal carotid artery aneurysm mimicking normal-tension glaucoma. Arq Bras Oftalmol. 2018;81(2):148-152. doi:10.5935/ 0004-2749.20180032

24. Nucci C, Aiello F, Giuliano M, Colosimo C, Mancino R. Ophthalmic segment of internal carotid artery aneurysm mimicking normal tension glaucoma. Int Ophthalmol. 2016;36(6):907-914. doi:10.1007/ s10792-016-0206-7

25. Hildebrand GD, Russell-Eggitt I, Saunders D, Hoyt WF, Taylor DSI. Bow-tie cupping: a new sign of chiasmal compression. Arch Ophthalmol Chic Ill. 2010;128(12):1625-1626. doi:10.1001/ archophthalmol.2010.291

26. Kalenak JW, Kosmorsky GS, Hassenbusch SJ. Compression of the intracranial optic nerve mimicking unilateral normal-pressure glaucoma. J Clin Neuroophthalmol. 1992;12(4):230-235; discussion 236-237.

27. Pellegrini F, Marullo M, Zappacosta A, Liberali T, Cuna A, Lee AG. Suprasellar meningioma presenting with glaucomatous type cupping. Eur J Ophthalmol. 2020. doi:10.1177/1120672120937674

28. Bianchi-Marzoli S, Rizzo JF, Brancato R, Lessell S. Quantitative analysis of optic disc cupping in compressive optic neuropathy. Ophthalmology. 1995;102(3):436-440. doi:10.1016/S0161-6420(95) 31003-2

29. Qu Y, Wang YX, Xu L, et al. Glaucoma-like optic neuropathy in patients with intracranial tumours. Acta Ophthalmol. 2011;89(5): e428-e433. doi:10.1111/j.1755-3768.2011.02118.x

30. Sommer A, Miller NR, Pollack I, Maumenee AE, George T. The nerve fiber layer in the diagnosis of glaucoma. Arch Ophthalmol Chic Ill. 1977;95(12):2149-2156. doi:10.1001/archopht.1977.04450120055003

31. Ahmed IIK, Feldman F, Kucharczyk W, Trope GE. Neuroradiologic screening in normal-pressure glaucoma: study results and literature review. J Glaucoma. 2002;11(4):279-286. doi:10.1097/00061198200208000-00002

32. Micieli JA, Margolin EA. Optic disc cupping due to dolichoectatic internal carotid artery optic nerve compression. J Neuro-Ophthalmol off J North Am Neuro-Ophthalmol Soc. 2020. doi:10.1097/ WNO.0000000000001113
33. Ogata N, Imaizumi M, Kurokawa H, Arichi M, Matsumura M. Optic nerve compression by normal carotid artery in patients with normal tension glaucoma. $\mathrm{Br} \quad J$ Ophthalmol. 2005;89(2):174-179. doi:10.1136/bjo.2004.047035

34. Umihira J, Oguchi K, Kurimoto Y, Matsuno K, Fukasaku K, Yoshimura N. Optic nerve compression by the internal carotid artery in patients with normal tension and high tension glaucoma. $\mathrm{Br}$ J Ophthalmol. 1999;83(11):1307-1308. doi:10.1136/bjo.83.11.1306b

35. Greenfield DS, Siatkowski RM, Glaser JS, Schatz NJ, Parrish RK. The cupped disc. Who needs neuroimaging? Ophthalmology. 1998;105(10):1866-1874. doi:10.1016/S0161-6420(98)91031-4

36. Lee AG. Differentiating glaucomatous from nonglaucomatous optic atrophy. Ophthalmology. 1999;106(5):855. doi:10.1016/S01616420(99)10109-X

37. Souto FMS, de Vasconcellos JPC, de Melo MB, Sartorato EL, Moura FC. Differentiating Leber hereditary optic neuropathy from normal-tension glaucoma. Neuro-Ophthalmol. 2017;41(2):99-102. doi:10.1080/01658107.2017.1279185

38. Lauer SA, Ackerman J, Sunness J, Bluth EM, Kim CK. Leber's optic atrophy with myopia masquerading as glaucoma: case report. Ann Ophthalmol. 1985;17(2):146-148.

39. Weiner NC, Newman NJ, Lessell S, Johns DR, Lott MT, Wallace DC. Atypical Leber's hereditary optic neuropathy with molecular confirmation. Arch Neurol. 1993;50(5):470-473. doi:10.1001/ archneur.1993.00540050022009

40. Opial D, Boehnke M, Tadesse S, et al. Leber's hereditary optic neuropathy mitochondrial DNA mutations in normal-tension glaucoma. Graefes Arch Clin Exp Ophthalmol. 2001;239(6):437-440. doi:10.1007/s004170100309

41. Ortiz RG, Newman NJ, Manoukian SV, Diesenhouse MC, Lott MT, Wallace DC. Optic disk cupping and electrocardiographic abnormalities in an American pedigree with Leber's hereditary optic neuropathy. Am J Ophthalmol. 1992;113(5):561-566. doi:10.1016/S0002-9394(14) 74730-0

42. Stelmach MZ, O'Day J. Partly reversible visual failure with methanol toxicity. Aust N Z J Ophthalmol. 1992;20(1):57-64. doi:10.1111/ j.1442-9071.1992.tb00705.x

43. Sharma M. Methanol-induced optic nerve cupping. Arch Ophthalmol. 1999;117(2):286. doi:10.1001/archopht.117.2.286

44. Shin YW, Uhm KB. A case of optic nerve atrophy with severe disc cupping after methanol poisoning. Korean J Ophthalmol. 2011;25 (2):146. doi:10.3341/kjo.2011.25.2.146

45. Sekkat A, Maillard P, Dupeyron G, Bensouda J, Arne JL, Bec P. [Optic neuropathy in acute poisoning with methanol]. $J \mathrm{Fr}$ Ophtalmol. 1982;5(12):797-804. French.

46. Senthil S, Turaga K. Bilateral normal tension glaucoma: can this be nutritional? Indian J Ophthalmol. 2017;65(7):625. doi:10.4103/ijo. IJO_794_16

47. O'Neill EC, Danesh-Meyer HV, Kong GXY, et al. Optic disc evaluation in optic neuropathies. Ophthalmology. 2011;118(5):964-970. doi:10.1016/j.ophtha.2010.09.002

48. Behbehani R. Clinical approach to optic neuropathies. Clin Ophthalmol Auckl NZ. 2007;1(3):233-246.

49. Fournier AV, Damji KF, Epstein DL, Pollock SC. Disc excavation in dominant optic atrophy. Ophthalmology. 2001;108:1595-1602.

50. Kim TW, Hwang JM. Stratus OCT in dominant optic atrophy: features differentiating it from glaucoma. J Glaucoma. 2007;16 (8):655-658. doi:10.1097/IJG.0b013e31804d23aa

51. Newman NJ, Lott MT, Wallace DC. The clinical characteristics of pedigrees of Leber's hereditary optic neuropathy with the 11778 mutation. Am J Ophthalmol. 1991;111(6):750-762. doi:10.1016/ S0002-9394(14)76784-4

52. Nagai-Kusuhara A, Nakamura M, Kanamori A, Nakanishi Y, Kusuhara S, Negi A. Evaluation of optic nerve head configuration in various types of optic neuropathy with Heidelberg Retina Tomograph. Eye. 2008;22(9):1154-1160. doi:10.1038/sj.eye.6702871 
53. Masvidal D, Parrish RK, Lam BL. Structural-functional dissociation in presumed ethambutol optic neuropathy. $J$ Neuroophthalmol. 2010;30(4):305-310. doi:10.1097/WNO.0b013e3181e08ecb

54. Olson JA. Walsh and Hoyt's clinical neuro-ophthalmology. $\mathrm{Br}$ J Ophthalmol. 1999;83(9):447-458. doi:10.1136/bjo.83.9.1096d

55. Gouda AS, Khattab AM, Mégarbane B. Lessons from a methanol poisoning outbreak in Egypt: six case reports. World J Crit Care Med. 2020;9(3):54-62. doi:10.5492/wjccm.v9.i3.54

56. Galvez-Ruiz A, Elkhamary SM, Asghar N, Bosley TM. Cupping of the optic disk after methanol poisoning. Br J Ophthalmol. 2015;99 (9):1220-1223. doi:10.1136/bjophthalmol-2014-306354

57. Hassanpoor N, Niyousha M. Severe optic disc cupping following the methanol toxicity in a 20-year-old man: a case report. Iran J Med Sci. 2021;46(5):395-398. doi:10.30476/IJMS.2021.88370.1914

58. Delirrad M, Mohammadi AB. New methanol poisoning outbreaks in Iran following COVID-19 pandemic. Alcohol Alcohol Oxf Oxfs. 2020;55(4):347-348. doi:10.1093/alcalc/agaa036

59. Hayreh MS. Methyl alcohol poisoning: III. Ocular Toxicity. Arch Ophthalmol. 1977;95(10):1851. doi:10.1001/ archopht.1977.04450100153022

60. Gupta PK, Asrani S, Freedman SF, El-Dairi M, Bhatti MT. Differentiating glaucomatous from non-glaucomatous optic nerve cupping by optical coherence tomography. Open Neurol J. 2011;5:1-7. doi:10.2174/1874205X01105010001

61. Rebolleda G, Noval S, Contreras I, Arnalich-Montiel F, García-Perez JL, Muñoz-Negrete FJ. Optic disc cupping after optic neuritis evaluated with optic coherence tomography. Eye. 2009;23 (4):890-894. doi:10.1038/eye.2008.117

62. Rath EZ, Rehany U, Linn S, Rumelt S. Correlation between optic disc atrophy and aetiology: anterior ischaemic optic neuropathy vs optic neuritis. Eye. 2003;17(9):1019-1024. doi:10.1038/sj.eye.6700691

63. Wilhelm H, Schabet M. The diagnosis and treatment of optic neuritis. Dtsch Aerzteblatt Online. 2015. doi:10.3238/arztebl.2015.0616

64. Arnalich-Montiel F, Muñoz-Negrete FJ, Rebolleda G, Sales-Sanz M, Cabarga C. Cup-to-disc ratio: agreement between slit-lamp indirect ophthalmoscopic estimation and stratus optical coherence tomography measurement. Eye Lond Engl. 2007;21(8):1041-1049. doi:10.1038/sj.eye. 6702391

65. Neubauer AS, Krieglstein TR, Chryssafis C, Thiel M, Kampik A. Comparison of optical coherence tomography and fundus photography for measuring the optic disc size. Ophthalmic Physiol Opt $\mathrm{J} \mathrm{Br}$ Coll Ophthalmic Opt Optom. 2006;26(1):13-18. doi:10.1111/j.14751313.2005.00339.x

66. Sebag J, Thomas JV, Epstein DL, Grant WM. Optic disc cupping in arteritic anterior ischemic optic neuropathy resembles glaucomatous cupping. Ophthalmology. 1986;93(3):357-361. doi:10.1016/S01616420(86)33735-7

67. Horowitz J, Melamud A, Sela L, Hod Y, Geyer O. Internal carotid artery hypoplasia presenting as anterior ischemic optic neuropathy. Am J Ophthalmol. 2001;131(5):673-674. doi:10.1016/S00029394(00)00886-2

68. Danesh-Meyer HV, Savino PJ, Sergott RC. The prevalence of cupping in end-stage arteritic and nonarteritic anterior ischemic optic neuropathy. Ophthalmology. 2001;108(3):593-598. doi:10.1016/ S0161-6420(00)00602-3

69. Hayreh SS, Jonas JB. Optic disc morphology after arteritic anterior ischemic optic neuropathy. Ophthalmology. 2001;108(9):1586-1594. doi:10.1016/S0161-6420(01)00649-2

70. Contreras I, Rebolleda G, Noval S, Mun oz-Negrete FJ. Optic disc evaluation by optical coherence tomography in nonarteritic anterior ischemic optic neuropathy. Investig Opthalmol Vis Sci. 2007;48 (9):4087. doi:10.1167/iovs.07-0171

71. Leaney JC, Nguyen V, Miranda E, et al. Bruch's membrane opening minimum rim width provides objective differentiation between glaucoma and nonglaucomatous optic neuropathies. Am J Ophthalmol. 2020;218:164-172. doi:10.1016/j.ajo.2020.05.034
72. Resch H, Mitsch C, Pereira I, et al. Optic nerve head morphology in primary open-angle glaucoma and nonarteritic anterior ischaemic optic neuropathy measured with spectral domain optical coherence tomography. Acta Ophthalmol. 2018;96(8):e1018-e1024. doi:10.1111/ aos. 13804

73. Hayreh SS. Posterior ischaemic optic neuropathy: clinical features, pathogenesis, and management. Eye. 2004;18(11):1188-1206. doi:10.1038/sj.eye.6701562

74. Sonty S, Schwartz B. Development of cupping and pallor in posterior ischemic optic neuropathy. Int Ophthalmol. 1983;6(3):213-220. doi:10.1007/BF00141130

75. Mansberger SL, MacKenzie PJ, Falardeau J. Optic disc cupping associated with neurosyphilis. J Glaucoma. 2013;22(2):80-83. doi:10.1097/IJG.0b013e3182311eb2

76. Rosdahl JA, Asrani S. Glaucoma masqueraders: diagnosis by spectral domain optical coherence tomography. Saudi J Ophthalmol. 2012;26 (4):433-440. doi:10.1016/j.sjopt.2012.08.006

77. Powell MR, Hurley LD, Richardson TC. An unusual complication of barotrauma at altitude. Aerosp Med Hum Perform. 2015;86 (11):994-998. doi:10.3357/AMHP.4359.2015

78. Chhablani P, Kekunnaya R. Neuro-ophthalmic manifestations of prematurity. Indian J Ophthalmol. 2014;62(10):992. doi:10.4103/ 0301-4738.145990

79. Jacobson LK, Dutton GN. Periventricular Leukomalacia. Surv Ophthalmol. 2000;45(1):1-13. doi:10.1016/S0039-6257(00)00134-X

80. Groth SL, Donahue SP, Reddy A, Sarma A, Wushensky C. Periventricular leukomalacia in patients with pseudo-glaucomatous cupping. $\mathrm{Am}$ J Ophthalmol. 2020;211:31-41. doi:10.1016/j.ajo.2019.10.016

81. Brodsky MC. Periventricular leukomalacia: an intracranial cause of pseudoglaucomatous cupping. Arch Ophthalmol. 2001;119(4):626. doi:10.1001/archopht.119.4.626

82. Ohno-Matsui K, Hirakata A, Inoue M, Akiba M, Ishibashi T. Evaluation of congenital optic disc pits and optic disc colobomas by swept-source optical coherence tomography. Investig Opthalmol Vis Sci. 2013;54(12):7769. doi:10.1167/iovs.13-12901

83. Rintoul AJ. Colobomatous cupping of the optic disc. $\mathrm{Br}$ J Ophthalmol. 1971;55(6):396-399. doi:10.1136/bjo.55.6.396

84. Hughes HL. A case of bilateral coloboma of the optic disc. $\mathrm{Br}$ J Ophthalmol. 1947;31(11):689-692. doi:10.1136/bjo.31.11.689

85. Mansoori T, Vemuganthi S, Agraharam S. Optic disc coloboma: glaucoma imitator. Indian $J$ Ophthalmol. 2019;67(10):1735. doi:10.4103/ijo.IJO_494_19

86. Lingam G. Pattern of blood vessels in eyes with coloboma. Indian J Ophthalmol. 2013;61(12):743. doi:10.4103/0301-4738.122910

87. Inoue M. Retinal complications associated with congenital optic disc anomalies determined by swept source optical coherence tomography. Taiwan J Ophthalmol. 2016;6(1):8-14. doi:10.1016/j.tjo.2015.05.003

88. Srinivasan G, Venkatesh P, Garg S. Optical coherence tomographic characteristics in morning glory disc anomaly. Can J Ophthalmol J Can Ophtalmol. 2007;42(2):307-309. doi:10.3129/can.j.ophthalmol.i07-031

89. Saraswat N, Ranjan R, Shukla D, Ojha S. Morning glory disc anomaly: a case report. Niger J Ophthalmol. 2017;25(1):42. doi:10.4103/ 0189-9171.207376

90. Amador-Patarroyo MJ, Pérez-Rueda MA, Tellez CH. Congenital anomalies of the optic nerve. Saudi $J$ Ophthalmol. 2015;29 (1):32-38. doi:10.1016/j.sjopt.2014.09.011

91. Sampaolesi R, Sampaolesi JR. Large optic nerve heads: megalopapilla or megalodiscs. Int Ophthalmol. 2001;23(4/6):251-257. doi:10.1023/A:1014409404579

92. Chen SJ, Lu P, Zhang WF, Lu JH. High myopia as a risk factor in primary open angle glaucoma. Int J Ophthalmol. 2012;5(6):750-753. doi:10.3980/j.issn.2222-3959.2012.06.18

93. Ding X, Chang RT, Guo X, et al. Visual field defect classification in the Zhongshan ophthalmic center-Brien Holden vision institute high Myopia Registry Study. Br J Ophthalmol. 2016;100(12):1697-1702. doi:10.1136/ bjophthalmol-2015-307942 
94. Senthil S, Nakka M, Sachdeva V, Goyal S, Sahoo N, Choudhari N. Glaucoma Mimickers: a major review of causes, diagnostic evaluation, and recommendations. Semin Ophthalmol. 2021;1-21. doi:10.1080/08820538.2021.1897855

95. Wang YX, Panda-Jonas S, Jonas JB. Optic nerve head anatomy in myopia and glaucoma, including parapapillary zones alpha, beta, gamma and delta: histology and clinical features. Prog Retin Eye Res. 2021;83:100933. doi:10.1016/j.preteyeres.2020.100933
96. Kim MJ, Kim SH, Hwang YH, Park KH, Kim TW, Kim DM. Novel screening method for glaucomatous eyes with myopic tilted discs: the crescent moon sign. JAMA Ophthalmol. 2014;132(12):1407. doi:10.1001/jamaophthalmol.2014.2860

\section{Publish your work in this journal}

Eye and Brain is an international, peer-reviewed, open access journal focusing on clinical and experimental research in the field of neuroophthalmology. All aspects of patient care are addressed within the journal as well as basic research. Papers covering original research, basic science, clinical and epidemiological studies, reviews and

Submit your manuscript here: https://www.dovepress.com/eye-and-brain-journal evaluations, guidelines, expert opinion and commentary, case reports and extended reports are welcome. The manuscript management system is completely online and includes a very quick and fair peerreview system, which is all easy to use. Visit http://www.dovepress. com/testimonials.php to read real quotes from published authors. 